\title{
Tratamentos superficiais visando à melhoria da aderência entre gesso e taliscas de bambu ${ }^{1}$
}

\author{
Cibelle G. Silva ${ }^{1}$, Normando P. Barbosa ${ }^{2} \&$ Marilia P. de Oliveira ${ }^{3}$
}

\section{RESU M 0}

0 gesso é um aglomerante com aplicações sobretudo na fabricação de placas de forro, elementos decorativos e em paredes divisórias. No entanto, utilizando-se de uma baixa relação água/gesso e procedimentos tais como vibração, torna-se possível obter resistências mecânicas compatíveis para outras aplicações na construção civil, como é o caso de elementos estruturais. A investigação reportada no presente trabalho teve como objetivo avaliar, experimentalmente, a possibilidade de se melhorar 0 compósito estudado. Foram realizados tratamentos para redução da absorção de água pelas taliscas, por meio da utilização de extrato vegetal $\mathrm{B}$ Carbon, resina polimérica e piche. $\mathrm{N}$ a tentativa de melhorar a aderência na interface gesso/bambu foram utilizados adesivo epóxi, massa plástica e piche, além de confeccionados corpos de prova de gesso reforçados com taliscas de bambu, tratadas com diferentes produtos, cuja eficiência foi avaliada em ensaios mecânicos. O bservou-se que, para ocorrer uma boa aderência na interface do compósito, são necessários tratamentos complementares que reduzam os efeitos da instabilidade dimensional.

Palavras-chave: absorção de água, instabilidade dimensional, compósito

\section{Surface treatments aimed at improving the adhesion between plaster and bamboo slivers}

\begin{abstract}
The gypsum is a binder with applications primarily in the manufacture of ceiling tile, decorative elements and partition walls. However, using a low water/plaster ratio and procedures such as vibration, it is possible to obtain mechanical strength compatible to other applications in construction as in the case of structural elements. The research reported in this study aimed to evaluate experimentally the possibility of improving the compound studied. Treatments were carried out to reduce water absorption by slivers through the use of plant extract B Carbon, polymer resin, and tar. In an attempt to improve the adhesion at the interface plaster/epoxy adhesive, bamboo, plastic and tar mass were used. Test specimens were made of plaster reinforced with slivers of bamboo, treated with different products, to assess its efficiency in mechanical tests. It was observed that to obtain a good adhesion at the interface of the composite it is necessary to apply additional treatments that reduce the effects of dimensional instability.
\end{abstract}

Key words: water absorption, dimensional instability, composite

${ }^{1}$ UFCG. Rua Maria Aparecida Carneiro 330, Ap. 302-A, Catolé, CEP 58410-367, Campina Grande, PB. Fone: (83)8815-1116, E-mail: cibelleguimaraes@yahoo.com.br

2 U FPB/CT, CEP 58050-900, João Pessoa, PB, Fone: (83) 9981-7225. E-mail: nperazzob@yahoo.com.br

3 U FERSA, Av. Francisco Mota, 572 ,Costa e Silva, CEP 59625-900, Mossoró, RN. Fone: (84) 3317-8322. E-mail: marilia@ufersa.edu.br 


\section{INTRODUÇÃO}

Em períodos remotos da história os materiais empregados em elementos mecânicos e estruturais variavam entre diferentes regiões, uma vez que sua utilização dependia da disponibilidade local. Observava-se que, de modo geral, em algumas regiões era intensa a utilização de materiais localmente disponíveis como pedra, aglomerantes naturais, madeira, terra crua, algodão, fibras naturais, fibras de coco, palha de trigo e casca de arroz etc. (Gavhami \& Marinho, 2005).

As construções em setores rurais dos países em desenvolvimento são caracterizadas pela utilização dos recursos disponíveis nos próprios locais. No Brasil, particularmente na região Nordeste, grande parte das construções rurais é feita com pedaços de galhos da vegetação local revestidos (pau a pique), realizados de forma empírica, o que faz com que essas construções tenham vida útil limitada.

Tais construções apresentam aparência precária, baixa resistência às intempéries e grande número de fissuras nas quais se alojam, usualmente, insetos transmissores de doenças e materiais industrializados mobilizam vastos recursos financeiros, o que torna seu uso proibitivo em micropropriedades geralmente pertencentes à população de baixa renda. Ainda se utilizam como agravante em tais construções, embora inadequadamente, materiais como o solo, a madeira e o bambu, por falta de conhecimento em relação às suas características. Apesar disto e com tais materiais e a um custo relativamente baixo, poder-se-ia obter construções seguras e duráveis (Lopes et al., 2002; Beraldo \& Rivero, 2003; Sudin \& Swamy, 2006; De Flander \& Roversa, 2009; Bonilla et al., 2010).

Os principais materiais para construção tais tais como cimento, concreto, aço, alumínio, materiais sintéticos, tintas, blocos e revestimentos cerâmicos, exigem investimentos vultosos, motivo pelo qual sua produção fica restrita a poucas pessoas. Cimento e aço são exemplos de oligopólios em nível mundial. Somem-se a isto outros aspectos negativos, tais como a enorme quantidade de energia necessária para produzi-los, as emissões de $\mathrm{CO}_{2}$ e a produção de resíduos ligados a esses materiais.

Desta forma, os materiais de construção industrializados são caros e ficam à margem de parcela significativa da população mundial. Neste sentido, torna-se evidente a necessidade de se utilizar materiais ecológicos que satisfaçam algumas exigências fundamentais para o futuro da humanidade, tais como: minimização do consumo de energia, conservação dos recursos naturais, redução da poluição e manutenção de um ambiente saudável (Ghavami, 2005).

Uma possibilidade de minimização do problema é o emprego não obrigatório de produtos à base de cimento Portland, nem de aço, nem de blocos cerâmicos mas também de materiais locais com os quais se possa construir apropriadamente, mesmo que esses últimos não recebem destaque nas escolas de Engenharia e de Arquitetura, haja vista que às grandes indústrias não interessa que outras opções sejam propostas para a construção; desta forma, materiais como a terra crua, o bambu e tantos outros de origem natural com os quais se poderia construir casas, são esquecidos.
O Brasil possui as maiores reservas de gipsita do mundo, segundo o Sumário Mineral de 2008 da U.S Geological Survey, porém a produção e o consumo ainda ainda são comparados aos de vários países. Os Estados Unidos é o maior produtor mundial, seguido da Espanha e do Irã, cujos dados mostram que ainda existe um potencial latente para o uso do gesso a a ser explorado no Brasil.

O gesso é considerado um aglomerante de muita eficiência energética, objeto de grande interesse para a sustentabilidade da construção pois no seu processo de fabricação enquanto o cimento Portland exige temperaturas da ordem de $1450{ }^{\circ} \mathrm{C}$, emitindo $\mathrm{CO}_{2}$ na atmosfera, o gesso pode ser obtido com menos de $170{ }^{\circ} \mathrm{C}$, liberando apenas v apor d'água na sua produção.

As propriedades mecânicas da pasta de gesso decrescem com o aumento da relação água/gesso. Desta forma, a quantidade de água na pasta de gesso influencia nas propriedades mecânicas do material endurecido (Rossler \& Older, 1989).

O polo do Araripe é a maior área produtora de gesso do Brasil, com 1,8 milhões de toneladas por ano. De acordo com o Sumário Mineral de 2008 do Departamento Nacional de Produção Mineral - DNPM, ele é localizado no sertão do Estado de Pernambuco, onde se concentram $85 \%$ da produção nacional. Na região produtora já se constroem casas com blocos de gesso nas quais, entretanto, a perda com corte de blocos e a durabilidade deveriam ser mais estudadas surgindo, então, a proposta de se fazer uso de vergas e contravergas com o próprio gesso reforçado com taliscas de bambu.ta

O bambu é um material de construção com ótimas propriedades mecânicas e que pode vir a reforçar elementos estruturais de concreto armado (Ghavami, 1995). Em contrapartida, esta aplicação tem sido limitada em virtude da baixa aderência verificada entre o bambu e o concreto. Ghavami (2005) afirmou que isto se deve, dentre outros fatores, às características higroscópicas apresentadas pelo bambu; outro fato que também prejudica o mecanismo de aderência bambuconcreto é a superfície lisa do vegetal. No caso de elementos estruturais de concreto armados submetidos à flexão, a redução da aderência é caracterizada pela diminuição da rigidez desses elementos (Macgregor, 1997). Tentando solucionar tais problemas, diversos pesquisadores vêm realizando novas pesquisas referentes ao tema, ao redor do mundo (Yu et al., 2003; Lima Jr. et al., 2005; Mesquita et al., 2006; Lima Jr. et al., $2008 ; 2010)$

Na matriz de gesso o bambu apresenta o mesmo o mesmo comportamento verificado quando é utilizado como reforço de peças de concreto, razão por que este trabalho defende propostas de tratamentos superficiais que possam melhorar a aderência do gesso com o bambu, em elementos estruturais horizontais de gesso.

\section{Material e MÉTOdos}

O gesso utilizado foi proveniente do polo gesseiro do Araripe, no estado de Pernambuco, disponível no comércio local. O gesso apresentava as seguintes características: módulo de finura de 0,08 , massa unitária $0,62 \mathrm{~g} \mathrm{~cm}^{-3} \mathrm{e}$ massa específica 
2,60 $\mathrm{g} \mathrm{cm}^{-3}$. De acordo com a análise química, os teores de óxido de cálcio $(\mathrm{CaO})$ de 43,26\% e anidrido sulfúrico $\left(\mathrm{SO}_{3}\right)$ de $54,96 \%$, atendem aos limites mínimos estabelecidos pela norma ABNT (1994), de 38,00 e 53,00\%, respectivamente. O bambu utilizado foi da espécie Bambusa vulgaris, coletado nos arredores do Campus I da Universidade Federal da Paraíba, João Pessoa.

\section{Tratamentos para redução de absorção de água pelo bambu}

Na tentativa de reduzir a absorção de água pelas taliscas de bambu, foram realizados os seguintes tratamentos:

1. Imersão em resina à base de silicone (vedacit)

2. Imersão em resina polimérica

3. Imersão em extrato vegetal B carbono (creosoto)

Para a aplicação dos tratamentos foram preparadas taliscas de bambu de $1 \mathrm{~cm}$ de espessura x $15 \mathrm{~cm}$ de comprimento.

\section{Imersão em resina à base de silicone}

A imersão em resina à base de silicone foi feita em quatro etapas, variando-se as imersões, em que na primeira etapa os corpos de prova foram submetidos a uma camada de resina em uma imersão, a segunda em duas imersões em intervalos de tempo de 10 min e assim sucessivamente, completando-se quatro etapas.

\section{Imersão em resina Polimérica}

A resina polimérica tem viscosidade mais elevada que a resina à base de silicone, motivo pelo qual foi feita apenas uma imersão, visto que seu alto grau de viscosidade impediria que a substância penetrasse nos poros do bambu, servindo apenas para formação de uma camada superficial.

\section{Impregnação em extrato vegetal B Carbon}

A impregnação com extrato vegetal (creosoto) foi realizada através da imersão das taliscas de bambu, nessa substância, durante $24 \mathrm{~h}$.

\section{Tratamentos superficiais para melhoramento da aderência}

Com o objetivo de melhorar a aderência bambu-gesso foram aplicados, às taliscas de bambu, tratamentos superficiais. Os tratamentos realizados foram massa plástica, cola epóxi e piche.

O bambu foi lixado para se retirar as camadas mais externas e regularizar sua superfície; em seguida, fez-se a imersão das taliscas nas substâncias citadas e depois se aspergiu areia, até preencher toda a superfície para deixar rugosa a superfície do tratamento.

\section{Moldagem das peças de gesso e taliscas de bambu Barras prismáticas reforçadas com taliscas de bambu}

Para os ensaios de tração na flexão (ABNT, 2005) foram moldadas barras prismáticas nas dimensões de 4 x 4 x $15 \mathrm{~cm}$, reforçadas com taliscas de bambu de aproximadamente $0,5 \times 13$ $\mathrm{cm}$ de comprimento (Figura 1). As taliscas de bambu foram submetidas a diferentes tratamentos superficiais com piche, massa plástica, cola epóxi e só então utilizadas em sua condição natural. A moldagem foi realizada com uma relação água/gesso de 0,3 , fazendo-se uso de mesa vibratória para melhor conformação do material visto que a quantidade de água de amassamento foi mínima. As taliscas de bambu foram colocadas na região inferior da seção reta em relação à linha neutra; por fim, foram utilizadas duas taliscas por corpo de prova.

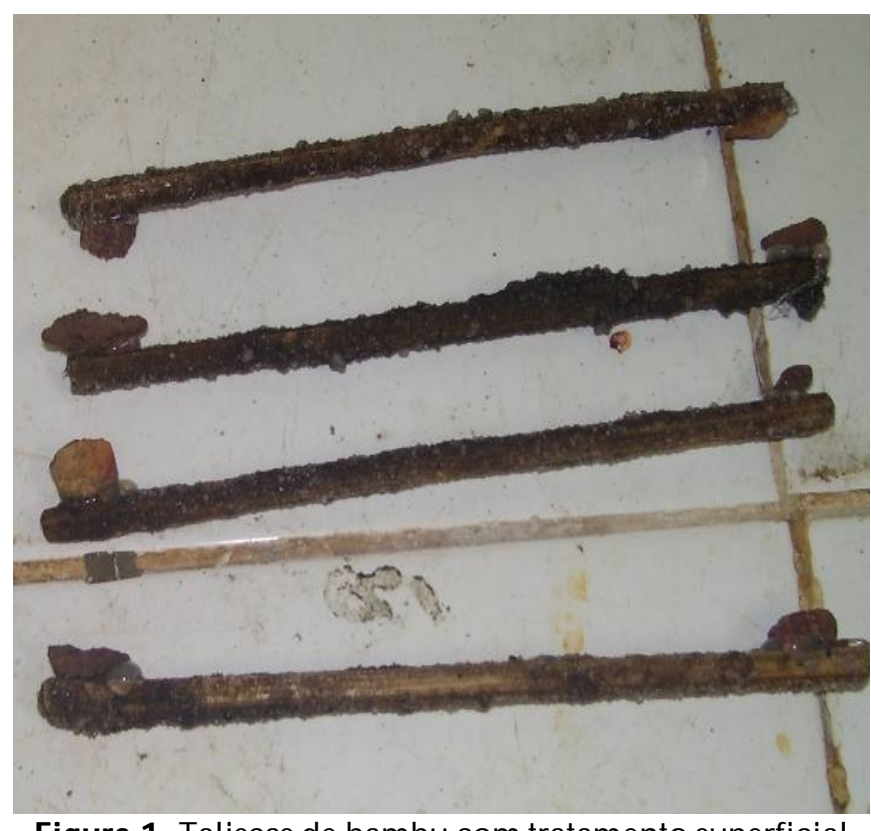

Figura 1. Taliscas de bambu com tratamento superficial utilizadas para reforço de barras prismáticas

\section{Corpos de prova para ensaio de aderência}

Os testes de aderência foram do tipo "push out" e confeccionados, também, corpos de prova cilíndricos, com 15 $\mathrm{cm}$ de diâmetro e $30 \mathrm{~cm}$ de altura com taliscas de bambu no seu centro, deixando-se cerca de $3 \mathrm{~cm}$ da talisca externamente ao corpo de prova.

As taliscas de bambu tinham largura aproximada de $2,5 \mathrm{~cm}$ e comprimento $36 \mathrm{~cm}$ e foram previamente lixadas para regularização da superfície, tendo-se retirado as camadas externas e, com uma fita crepe, foram isoladas as extremidades das taliscas deixando-se apenas os $10 \mathrm{~cm}$ centrais livres.

Para cada tratamento foram preparados dois tipos de amostras com ranhuras horizontais e sem ranhuras, conforme a Figura 2.

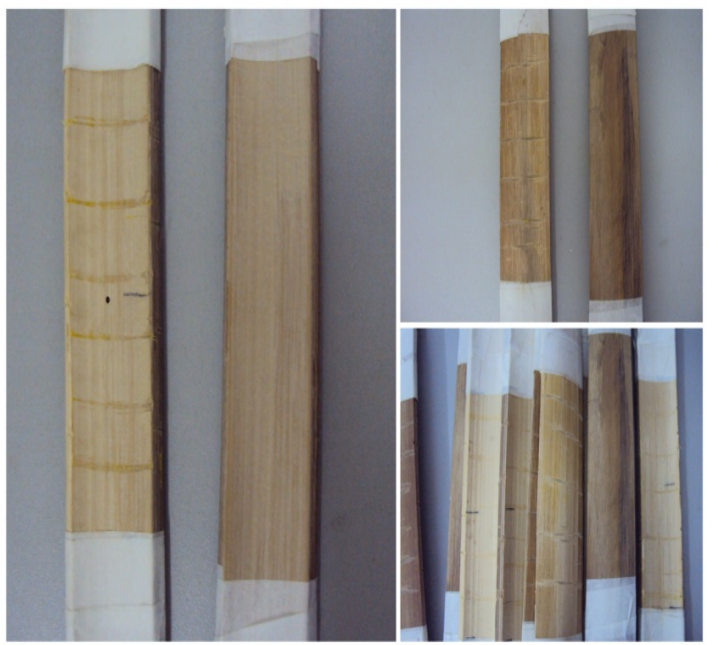

Figura 2. Talisca de bambu com ranhura e sem ranhura 
Os tratamentos utilizados foram com piche, cola epóxi e massa plástica, com aspersão de areia nas superfícies tratadas. A forma foi aperfeiçoada para execução da moldagem (Figura 3), após a qual os corpos de prova (Figura 4, direita) foram deixados no ambiente durante 8 dias e, em seguida, colocados em estufa a $55^{\circ} \mathrm{C}$, durante 24 h para só então então serem submetidos ao ensaio de aderência.

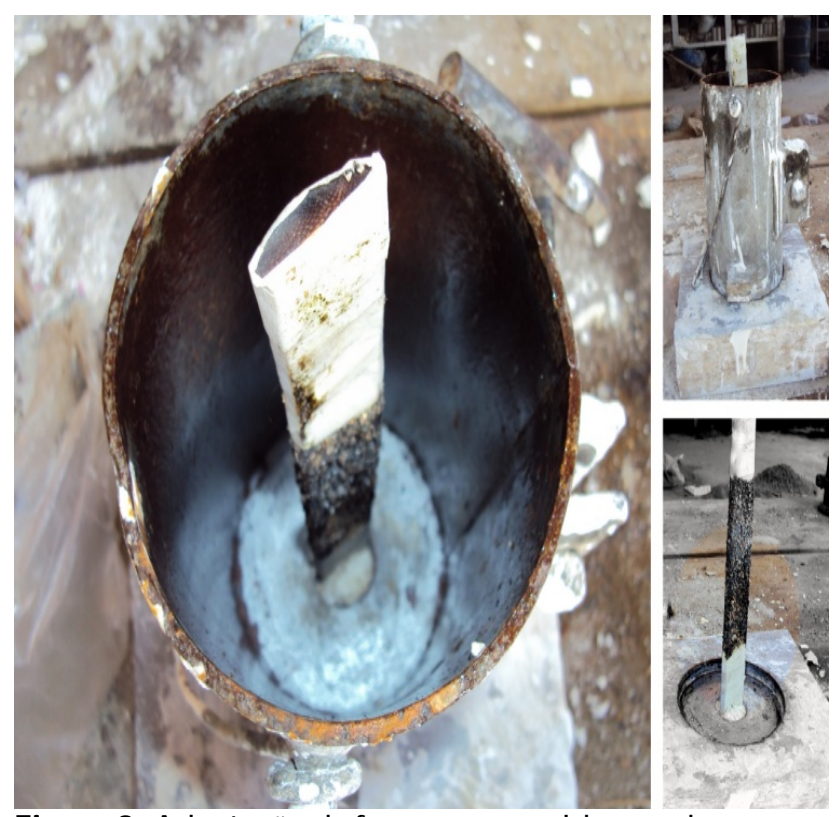

Figura 3. Adaptação da forma para moldagem dos corpos de prova para o ensaio de arrancamento "pushout"

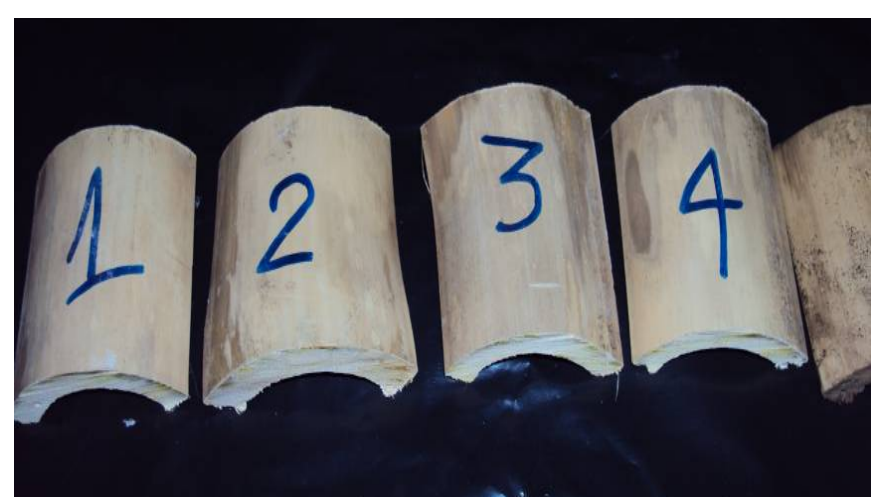

Figura 4. Partes de colmos de bambu cortados para ensaio de variação dimensional

\section{Análise da variação dimensional}

O objetivo do ensaio de variação dimensional foi determinar os valores percentuais de absorção de água e de variação dimensional, espécie Bambusa vulgaris utilizada nesta pesquisa.

A partir de amostras retiradas do meio dos colmos foram confeccionados corpos de prova com dimensões de aproximadamente $60 \mathrm{~mm}$ na direção longitudinal às fibras e 50 $\mathrm{mm}$ transversalmente às mesmas (Figura 4). Os corpos de prova de bambu foram submetidos às seguintes condições ambientais:

\section{Temperatura ambiente}

Secagem em estufa $\left(55^{\circ} \mathrm{C}\right)$ : para determinar a variação dimensional das partes dos colmos de bambu
Imersão durante $24 \mathrm{~h}$ visando determinar a absroção a absorção de água pelas partes dos colmos do bambu

As medições foram realizadas em duas direções anatômicas principais, ou seja, na longitudinal (paralela as fibras) e na transversal (espessura do colmo). Os corpos de prova foram pesados nas três condições ambientais e com esses dados foram calculadas as variações dimensionais dos corpos de prova.

Ensaio de resistência à tração, na flexão em barras prismáticas

A resistência à tração na flexão foi determinada de acordo com a ABNT (2005); neste ensaio um carregamento central é aplicado ao corpo de prova prismático que, por sua vez, é posto sobre dois apoios com $100 \mathrm{~mm}$ de vão entre si; o equipamento utilizado para o ensaio de flexão em três pontos foi uma prensa da marca Versa-Tester.

\section{Teste de aderência por arrancamento (push-out test)}

Os corpos de prova foram apoiados sobre uma chapa metálica dispondo de um orifício de cerca $2 \mathrm{~cm}$ para permitir o deslocamento da talisca (Figura 5);(9 a força era aplicada na parte superior, obtendo-se o valor máximo da carga que provocava a separação dos dois materiais; a resistência de aderência era medida dividindo-se a força máxima indicada no equipamento pela área de contato entre os materiais.
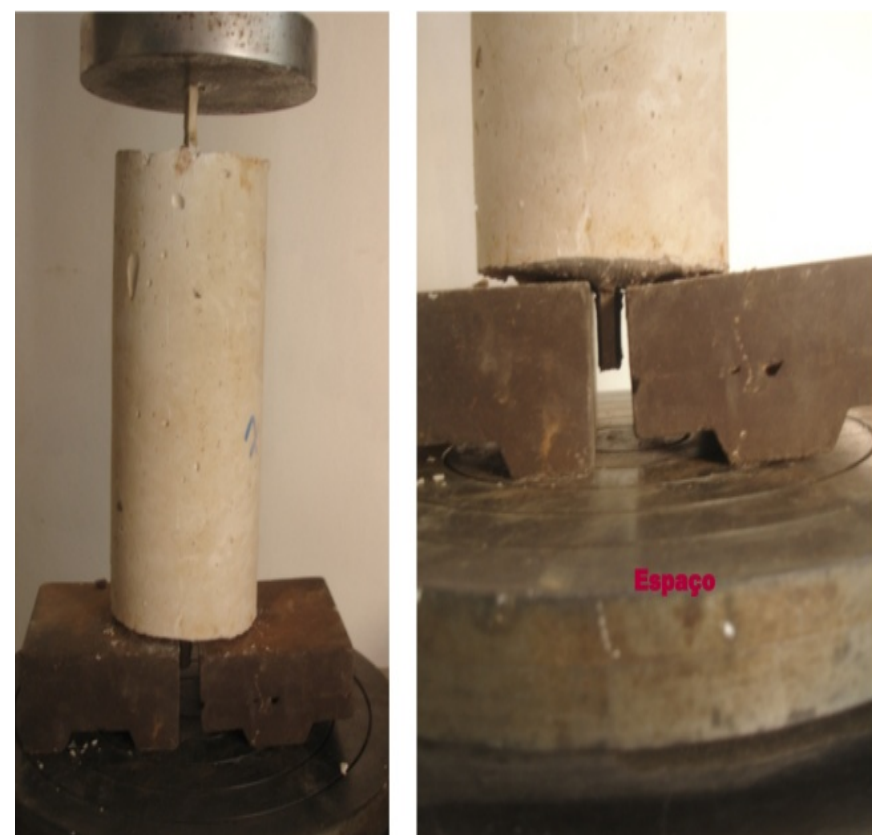

Figura 5. Talisca de bambu submetidas ao ensaio de arrancamento "push-out"

\section{RESULTADOS E DISCUSSÃO}

\section{Efeito dos tratamentos superficiais na absorção de água pelo bambu}

A resina antifungo reduziu cerca de $10 \%$ da absorção de água se comparada com a amostra natural; quanto às imersões realizadas, praticamente não houve influência; no tratamento com a resina de poliéster o bambu apresentou absorção de água da ordem de $12 \%$ mas após 24 h de imersão em água a 
película que recobria o bambu separou-se da superfície. O extrato vegetal, que dentre as substâncias utilizadas foi a que apresentou a maior viscosidade, reduziu a absorção para $6,5 \%$; na Figura 6 observa-se que o tratamento superficial que mostrou mais eficiência na redução de absorção do bambu foi a impregnação em extrato vegetal; esta variação de eficácia de tratamentos diferentes também foi constatada por Toledo Filho \& Barbosa (1990) e Barbosa et al. (1995); esses autores obtiveram, para a mesma espécie de bambu, uma absorção variando de 4 a $16 \%$, sendo o menor valor correspondente ao piche.

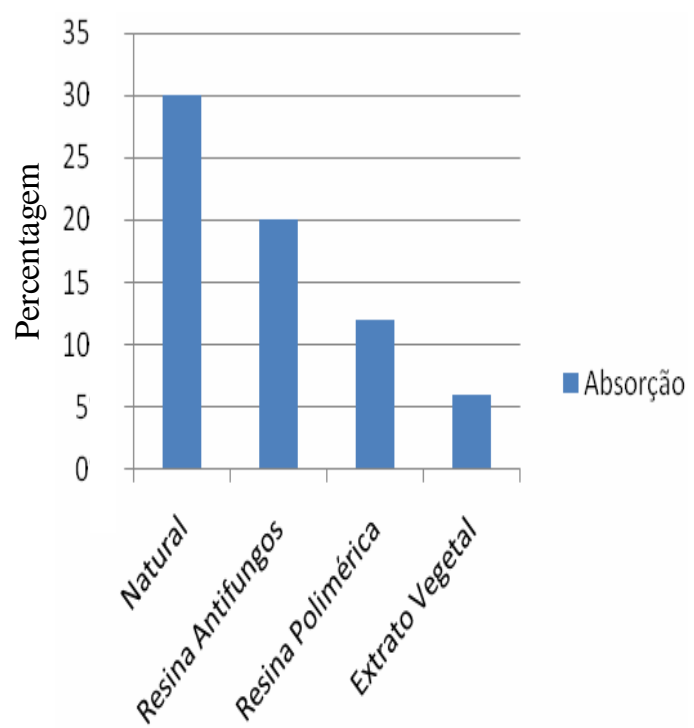

Figura 6. Comparativo dos tratamentos superficiais para redução de água após 24 h de imersão

\section{Variação dimensional}

Verifica-se, na Figura 7, que a retração transversal (ao longo da espessura da parede) foi reduzida para os tratamentos com cola époxi e piche.



Figura 7. Comparativo da retração nas amostras de bambu submetidas a diferentes tratamentos superficiais

Na direção longitudinal as variações foram limitadas, como já constatado por Barbosa et al. (1995), mesmo se usando, naquele trabalho, outro tipo de corpo de prova, como neste

tratamento com piche, que foi o que conduziu ao melhor resultado.

Os tratamentos superficiais com cola epóxi e com m assa plástica apresentaram efeito indesejável após sua imersão em água por $24 \mathrm{~h}$, de vez que ambos apresentaram fissuras na camada superficial; por se tratar de materiais rígidos, qualquer variação de volume do bambu provoca, ao absorver água, a ruptura da capa superficial formada pelo tratamento.

Na Figura 8A, observa-se a presença de fissuras na camada superficial de cola epóxi, provocadas pela expansão do bambu na direção transversal, fato já esperado, visto que no tratamento com cola epóxi a retração transversal foi de $5 \%$ enquanto a longitudinal foi de $1 \%$. Na Figura 8B tem-se o mesmo efeito com a camada superficial de massa plástica com a diferença de que, além do surgimento de fissuras, também se observou o descolamento da camada superficial, o que demonstra a falta de aderência entre a massa plástica e o bambu.

A.

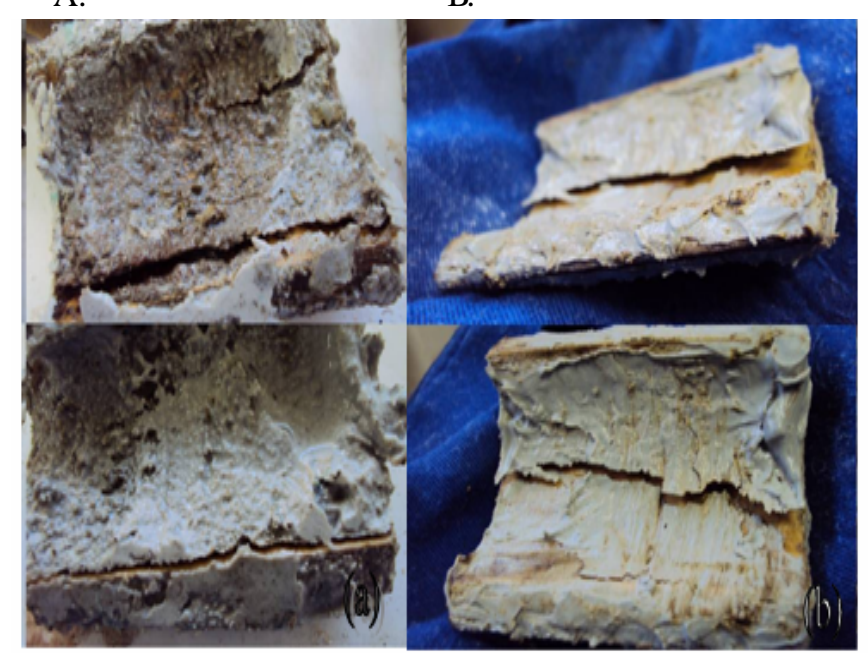

Figura 8. Fissuras na camada superficial do bambu tratado com epóxi (A) e massa plástica (B) após imersão em água por $24 \mathrm{~h}$

A Figura 9 apresenta um comparativo da resistência à tração na flexão estática entre os corpos de prova rr Reforçados com

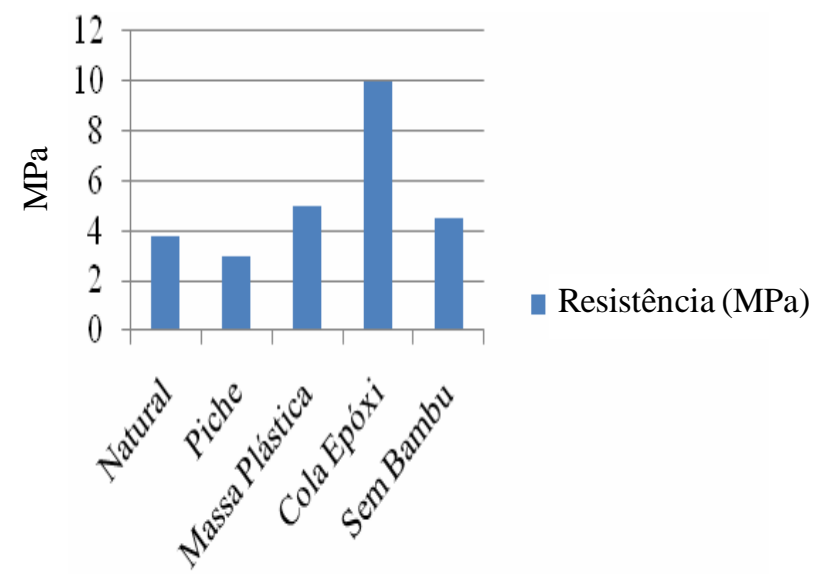

Figura 9. Resistência a tração na flexão para os corpos de prova de gesso com taliscas de bambu tratadas e no estado natural 
taliscas de bambu e submetidos a diferentes tratamentos superficiais. Pode-se observar, ainda, que a utilização de taliscas naturais e tratadas com emulsão à base de piche diminuiu a resistência mecânica se comparadas com o corpo de prova só de gesso, sem reforço detaliscas bambu. A superfície lisa do material mostrou completa falta de aderência com o gesso, o que foi agravado com o tratamento à base de piche que, por se tratar de uma substância oleosa, pode ter facilitado o escorregamento na interface gesso/bambu.

A cola epóxi foi o tratamento que mostrou melhor eficiência, conseguindo duplicar o valor da resistência em relação ao material sem reforço. Este fato pôde ser comprovado através da visualização da propagação das fissuras (Figura 10); outrossim, as fissuras na ruptura dos corpos de prova com o bambu tratado com cola epóxi, apresentaram fissuras a $45^{\circ}$, iniciando-se na aplicação da força até as regiões dos apoios. Ficou evidente que o bambu e o gesso se estão deformando juntos; os demais tratamentos apresentaram fissura central podendo-se notar, no ensaio, que os materiais não mostravam uma aderência adequada.

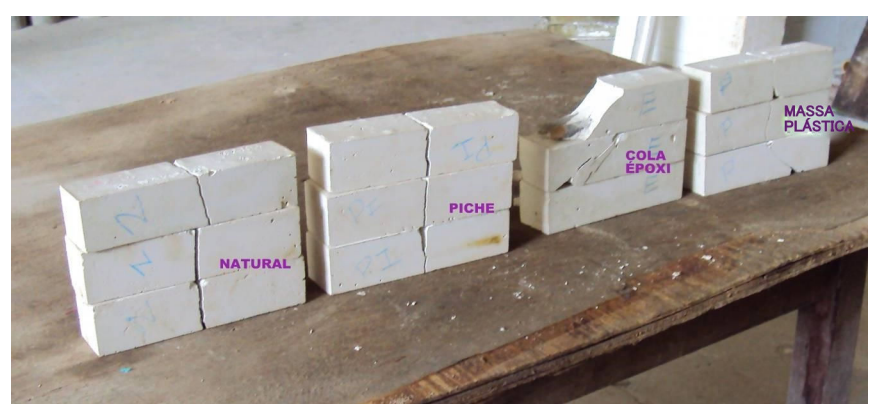

Figura 10. Propagação das fissuras nos corpos de prova reforçados com bambu submetidos a diferentes tipos de tratamento

\section{Teste de arrancamento (push-out test)}

As tensões de aderência das taliscas para os diversos tratamentos testados podem ser observadas na Figura 11.

Observando-se o gráfico da Figura 11, percebe-se que os resultados para os corpos de prova com taliscas tratadas com piche e na condição natural sem ranhura, não estão representados uma vez que não foi possível efetuar-se a leitura

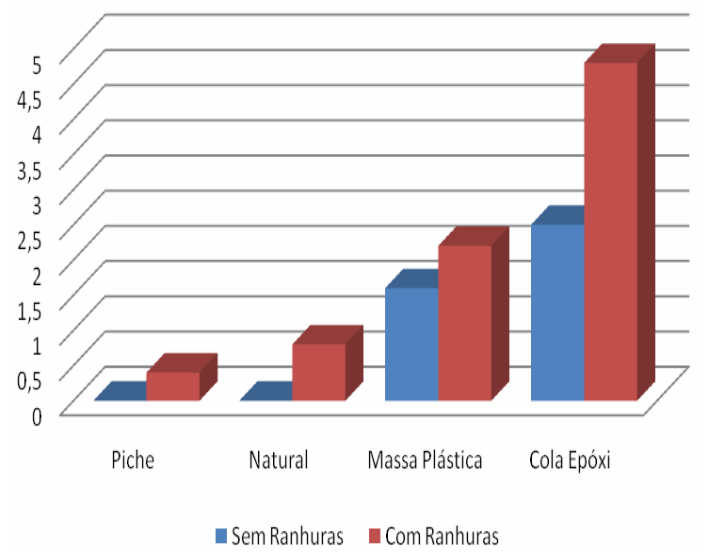

Figura 11. Tensão de aderência máxima para cada tipo de tratamento das forças nessas condições visto que a talisca começou a deslizar com um esforço muito pequeno, indicando que a aderência foi quase nula. As amostras no estado natural e com tratamento de piche com ranhura apresentaram resultados muito baixos, sinalizando a falta de eficiência desse tratamento.

Confirmando os resultados obtidos nos ensaios de flexão estática, as amostras com tratamento com cola epóxi apresentaram os valores mais elevados e a presença de ranhura aumentou em $40 \%$ a tensão máxima de aderência do bambu com o gesso.

Pôde-se observar que a ruptura dos corpos de prova de bambu tratado com massa plástica se deve à falta de aderência entre a massa plástica e o bambu, enquanto para as amostras com cola epóxi a falha ocorreu entre a camada superficial (cola epóxi) e o gesso, porém já com tensões de aderência relativamente altas. Mesquita et al. (2006) obtiveram valores próximos a $2 \mathrm{MPa}$ para tensões de aderência média entre o bambu e o concreto com resistência similar à do gesso obtido neste trabalho. Por sua vez, Lopes et al. (2002) fizeram ensaios similares com taliscas de bambu imersas em solo-cimento e obtiveram valores aproximados a $1 \mathrm{MPa}$.

Outro fato interessante se deve ao modo de ruptura das amostras tratadas com a cola epóxi. Como se observa na Figura 12, a ruptura se deu no local de transição entre a fita crepe, que isolava a porção da talisca de bambu não tratada, daquela que recebeu o tratamento.
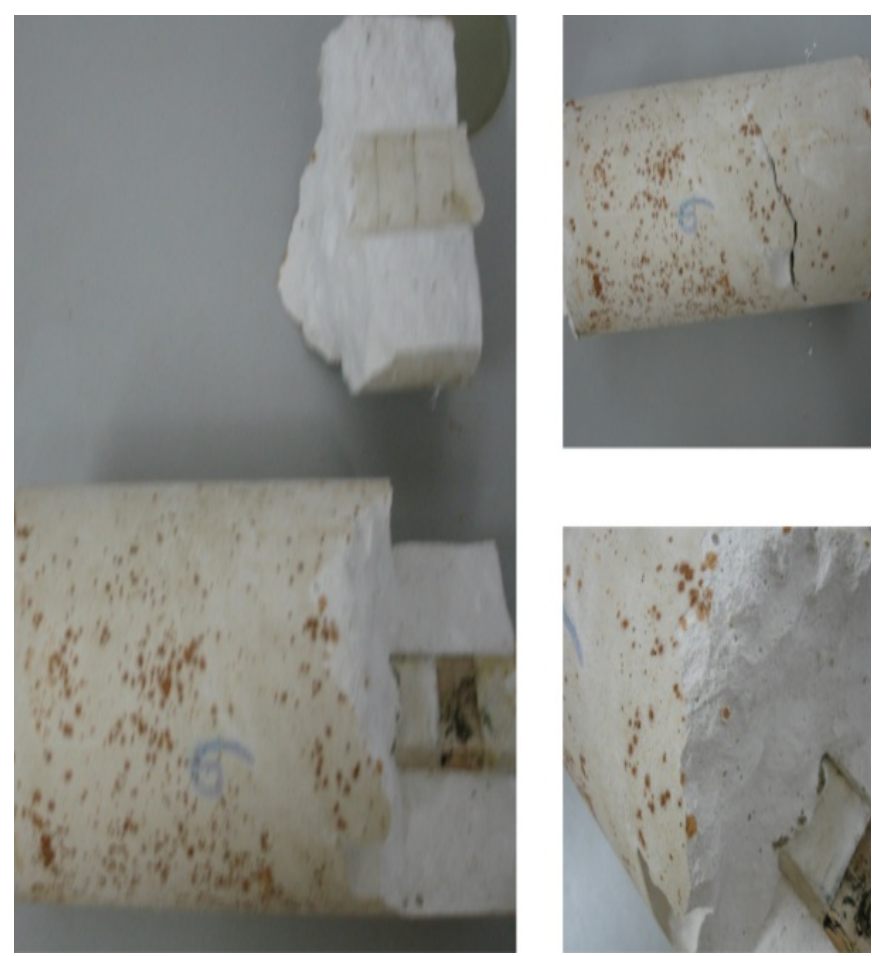

Figura 12. Ruptura nos corpos de prova com taliscas tratadas com cola epóxi e areia

\section{CONCLusões}

1. É possível aumentar tensões de aderência de taliscas de bambu imersas no gesso, de tal ordem de grandeza a fazer com que o bambu possa servir como reforço em elementos 
construtivos de gesso submetidos a flexão, tais como vigas para aplicação nas construções rurais.

2. É necessário efetuar-se o tratamento das taliscas de bambu para reduzir a absorção de água e, consequentemente, minimizar as variações dimensionais que prejudicam as interações gesso/bambu.

3. Um tratamento que reduza a absorção d'água não implica, necessariamente, melhoria na aderência; tratamento à base de piche diminuiu a absorção d'água mas permitiu o deslizamento das taliscas.

4. O tratamento com epóxi e areia mostrou-se eficaz, promovendo uma aderência adequada entre a talisca de bambu e o gesso.

\section{Agradecimentos}

À Rede Brasileira do Bambu/CNPq; à CAPES Proengenharia e à COFECUB, pelo apoio à investigação.

\section{LITERATURA CITADA}

ABNT - Associação Brasileira de Normas Técnicas. Gesso para construção civil: especificação. NBR 13207. Rio de Janeiro: ABNT. 1994. 9p.

ABNT - Associação Brasileira de Normas Técnicas. Argamassa para assentamento e revestimento de paredes e tetos determinação da resistência à tração na flexão e à compressão. NBR 13279. Rio de Janeiro: ABNT. 2005. 2p.

Barbosa, N. P.; Toledo Filho, R. D.; Khavami. K. Vigas de concreto laterítico reforçados com bambu. In: Reunião anual do IBRACOM,, 33, 1995, Santos. Anais....Santos: IBRACOM, 1995, v.2, p.341-345.

Beraldo, A. L.; Rivero, L. A. Bambu laminado colado (BLC). Floresta e Ambiente, v.10, p.36-46, 2003.

Bonilla, S. H.; Guarnetti, R. L.; Almeida, C. M. V. B.; Giannetti, B. F. Sustainability assessment of a giant bamboo plantation in Brazil: exploring the influence of labour, time and space. Journal of Cleaner Production, v.18, p.83-91, 2010.

De Flander, K.; Roversa, R. One laminated bamboo-frame house per hectare per year. Construction and Building Materials, v.23, p.210-218, 2009.

Ghavami, K. Ultimate load behavior of bamboo-reinforced lightweight concrete beams. Cement and Concrete Composites, v.17, p.259-351, 1995.
Ghavami, K.; Bamboo as reinforcement in structural concrete elements. Cement and Concrete Composites, v.27, p.637$649,2005$.

Ghavami, K.; Marinho, A. B. Propriedades físicas e mecânicas do colmo inteiro do bambu da espécie Guadua angustifolia. Revista Brasileira de Engenharia Agrícola e Ambiental, v.9, p.107-114, 2005.

Lima Jr., H. C.; Willrich, F. L.; Barbosa, N. P.; Rosa, M. A.; Cunha, B. S. Durability analysis of bamboo as concrete reinforcement. Materials and Structures, v.41, p.805-999, 2008.

Lima Jr., H. C.; Willrich, F. L.; Fabro, G. Vigas de concreto reforçadas com bambu Dendrocalamus giganteus. II: modelagem e critérios de dimensionamento. Revista Brasileira de Engenharia Agrícola e Ambiental, v.9, p.652-659, 2005.

Lima Jr., H. C.; Willrich, F. L.; Fabro, G.; Rosa, M. A.; Tanabe, L. K.; Sabino, R. B. G. Análise mecânica de pilares mistos bambu-concreto. Revista Brasileira de Engenharia Agrícola e Ambiental, v.14, p.545-553, 2010.

Lopes, W. G. R.; Freire, W. J.; Ferreira, G. C. S. Ensaios de arrancamento e de empuxamento aplicados a taliscas de bambu. Revista Brasileira de Engenharia Agrícola e Ambiental, v.6, p.504-510, 2002.

Lopes, W. G. R.; Freire, W. J.; Ferreira, G. C. S. Ensaios de arrancamento e de empuxamento aplicados a taliscas de bambu. Revista Brasileira de Engenharia Agrícola e Ambiental, v.6, p.504-510, 2006.

Macgregor, J. G. Reinforced concrete, mechanics and design. New Jersey: Prentice Hall, 1997. 939p.

Mesquita, L. P.; Czarnieski, C. J.; Braga Filho, A. C.; Willrich, F. L.; Lima Jr., H. C.; Barbosa, N. P. Determinação da tensão de aderência do bambu-concreto. Revista Brasileira de Engenharia Agrícola e Ambiental, v.10, p.505-516, 2006.

Rossler, M.; Older, I. Relationships between pore structure and strength of set gypsum pastes Part I: Influence of water/ gypsum ratio and temperature, Zement-Kalks-Gips, v.2, p.96100, 1989.

Sudin, R.; Swamy, N. Bamboo and wood fibre cement composites for sustainable infrastructure regeneration. Journal of Materials Science, v.41, p.6917-6924, 2006.

Toledo Filho, R. D.; Barbosa, N. P. Aplicação do bambu e de fibras naturais nas construções rurais. In: Congresso Brasileiro de Engenharia Agrícola, 19, 1990, Piracicaba. Anais...Piracicaba: SBEA, 1990. CD-Rom.

Yu, W. K.; Chung, K. F.; Chan, S. L. Column buckling of structural bamboo. Engineering Structures, v.25, p.755-768, 2003. 